\title{
EL CONTROL JURISDICCIONAL Y PARLAMENTARIO DE LOS DECRETOS LEGISLATIVOS
}

\author{
POR \\ JAVIER JIMENEZ CAMPO \\ Universidad Complutense
}

\begin{abstract}
SUMARIO
I. INTRODUcción: A) La constitucionalización de la delegación legislativa. B) La función normativa del gobierno como problema fundamental en los ordenamientos contemporáneos. C) Algunas peculiaridades en el derecho español.-II. LOS DECRETOS LEgISLATIVOS COMO FUENTE DEL DERECHO. Su locaLIZACIón EN el SISTEMa CONSTITUCIONAL: A) Conveniencia de una reconstrucción dogmática de la figura. B) Exposición y crítica de algunos planteamientos doctrinales. C) Los decretos legislativos en la crisis de la categoría "fuerza de ley».-III. UNA FóRMULA DE AJUSTE ENTRE EL CONTROL DE LEGalidad Y EL CONTROL DE CONSTTTUCIONALIDAD: A) Dificultades de una delimitación de competencias según criterios preconstitucionales. B) El sentido de la intervención de la jurisdicción ordinaria en la nueva estructura constitucional.-IV. EL CONTrol PARLAMENTARIo: A) Consideraciones generales. B) Control político y control jurídico. Control y jurisdicción. C) Articulación del control parlamentario.
\end{abstract}

\section{INTRODUCCION}

A) Seguramente no es aventurado afirmar que en los artículos 82 a 85 de la Constitución se encuentra una de las regulaciones de mayor trascendencia para la correcta comprensión - y para la plasmación eficaz- de la forma de gobierno que delinea nuestro texto fundamental. Por ello, y porque en los mencionados preceptos no dejan de presentarse algunos puntos de controvertida significación, debe el intérprete esforzarse por encontrar el sentido del instituto de la delegación legislativa en nuestro derecho, y ello sin perder de vista en ningún momento la nueva configuración institucional vigente -o propugnada, al menos- desde diciembre de 1978. Por lo demás, el hecho de que en el ordenamiento del régimen anterior la delegación legislativa hubiese alcanzado un pleno reconocimiento jurídico (arts. 10.4 de la Ley de Régimen Jurídico de la Administración del Estado, de 1957, y 51 de 
la Ley Orgánica del Estado), así como una aplicación frecuentemente irregular, habrá de ser tenido en cuenta para compulsar —una vez más- la distancia entre «lo nuevo» y «lo viejo» y para apreciar, en consecuencia, la adecuación o no de los anteriores esquemas doctrinales y jurisdiccionales a la actual estructura constitucional.

En todo caso, con carácter general, es notorio que estamos ante un problema que arrastra su condición polémica a lo largo de toda la historia del constitucionalismo moderno y que en nuestros días - de acuerdo con las transformaciones en las funciones y estructuras del Estado- adquiere relevancia especial. Un problema - hay que subrayarlo desde ahora- en el que las soluciones dogmáticas han estado siempre en función del entendimiento, en un sentido u otro, de las relaciones interorgánicas en el seno del Estado, cuando no de la respuesta dada a la cuestión misma de la soberanía. Es así como hay que entender todo el debate en Francia, bajo la III y la IV Repúblicas, en torno a la normación con fuerza de ley del ejecutivo - difícilmente conciliable con la tesis de la delegación en las Cámaras, por parte de la nación soberana, de la potestad legislativa ${ }^{1}$ - , y otro tanto cabría decir para el derecho británico y la tensión presente en el mismo entre el viejo principio de raíz lockiana, según el cual sería tarea del Parlamento to make laws and not to make legislators, y la creciente necesidad de atribuir facultades normativas a un gobierno desprovisto de potestad reglamentaria originaria. Es toda la construcción doctrinal de la delegación legislativa - sus límites, su control, su singularización respecto de la atribución de plenos poderes y de la transferencia de potestades- la que depende de estos datos institucionales primarios que quedan articulados en una concreta forma de gobierno, y recordarlo debe ser sobre todo una advertencia para no universalizar las categorías jurídicas al margen de su específica funcionalidad histórica. Sin duda es indispensable el esfuerzo conceptual en este campo - -seguir distinguiendo, por ejemplo, entre delegación y autorización y emancipar la primera de la figura privatista del mandato ${ }^{2}-$, pero ello debe hacerse con la voluntad de procurar un reencuentro entre la cultura jurídica y la realidad constitucional en transformación, más urgente,

${ }^{1}$ La polémica sobre los decretos-leyes dutante la III y la IV República está ampliamente tratada en J. Soubeyrol, Les Décrets-lois sous la Quatrième République, Burdeos, 1955 , págs. 22 y ss.

2 Para la distinción clásica entre delegación y autorización, cfr. Santi Romano, «Saggio di una teoria sulle leggi di approvazione» (1898), recogido hoy en Scritti minori, vol. I, Milán, 1950, págs. 51 y ss. También la distinción en E. Tosato, Le leggi di delegazione, Padua, 1931, pág. 18. En cuanto a la inadecuación de la noción de mandato para dar cuenta del carácter y contenido del fenómeno de la delegación, hay un práctico total acuerdo en la doctrina. Una de las consecuencias del rechazo de esta categorización es la de que la delegación subsiste, en tanto no sea revocada, pese a las transformaciones personales en los órganos delegante y delegado; sin embargo - como evidencia de la interpenetración entre formalizaciones jurídicas $\mathrm{y}$ exigencias políticas en este terreno-, debe señalarse lo dispuesto en el artículo 168 de la Constitución portuguesa de 1976: «1. La Asamblea de la República podrá autorizar al Gobierno a elaborar decretos-leyes sobre materias de su competencia exclusiva, si bien deberá definir el objeto y la extensión de la autorización, así como su duración, que podrá ser prorrogada. (...). 3. Las autorizaciones caducarán al ser relevado el Gobierno al que hubieren sido concedidas, al expirar la legislatura o al ser disuelta la Asamblea de la República.» 
si cabe, cuando estos cambios se formalizan mediante la adopción de un nuevo texto constitucional.

B) No puede entenderse el sentido y el alcance de la delegación legislativa si no se la sitúa en el contexto general de la función normativa del gobierno. Es bien conocido que la ampliación contemporánea de tal normación ha venido produciéndose, en los diversos ordenamientos, a través de vías diferentes y con títulos también distintos. En unos casos -y el ejemplo típico es la Constitución francesa de 1958 - ha sido la potestad reglamentaria del gobierno la que se ha visto fortalecida frente a la primacía de la ley del Parlamento ${ }^{3}$; en otros - es el caso italiano, por ejemplo-, el instituto de la decretación de urgencia se ha visto desvirtuado de su fundamentación inicial para pasar a convertirse, en virtud de su instrumentación gubernamental, en un medio más de intervención legislativa ordinaria, y ello en menoscabo de la primacía reconocida a las Cámaras en el proceso normativo ${ }^{4}$; las fórmulas de delegación, en fin, tanto cuando dan lugar a la adopción por el gobierno de normas de mero rango reglamentario (art. 80 de la Grundgesetz y, con carácter general, los statutory instruments británicos) como cuando habilitan a aquél para dictar disposiciones con fuerza de ley, se constituyen en el tercer instrumento hacia la señalada potenciación del papel normativo del ejecutivo. Sería aquí ocioso cualquier abundamiento en las condiciones sociales y políticas que están en la base de este protagonismo gubernamental en el proceso normativo ${ }^{5}$ y que, en todo caso, tiene también una de sus verificaciones más importantes en la no infrecuente pérdida por parte de las asambleas del control sobre el iter formativo de la ley (confección del orden del día, restricción del poder de enmienda y de iniciativa, etc.). Lo que sí tiene más interés para nuestro objeto es la advertencia de la efectividad constitucional de las diferentes vías aludidas. Con ello quiere señalarse, en primer lugar, que, por encima de prohibiciones expresas y más allá de cualquier concepción rígida de la separación de poderes, la intervención normativa del ejecutivo se evidencia

${ }^{3}$ Para el caso francés bajo la Constitución de 1958, sin embargo, debe pasarse del estudio de las disposiciones constitucionales al análisis de su verificación concreta. En este sentido, no puede hablarse de una crisis general de la primacía de la ley por efecto del juego de la reserva reglamentaria. Ello se debe al carácter expansivo del ámbito de la legalidad que resulta tanto de la escasa utilización de los mecanismos constitucionales en defensa de la reserva reglamentaria (art. 37, sobre todo) como de la incorporación por el Consejo Constitucional de los principios generales del derecho a la lista de materias reservadas a la ley. Sobre el tema puede verse M. H. Fabre, «La loi, expression de la souveraineté», en Revue du Droit Public, núm. 2, 1979, págs. 341-347.

${ }_{4} \ll \mathrm{A}$ falta de una mayoría gubernamental cierta y leal -señala S. Tosi-, el ejecutivo recurre frecuentemente a los decretos-leyes, a los que no ve sino como proyectos de ley reforzados, que confía en ver prosperat rápidamente mediante el procedimiento de ratificación en sesenta días»; cfr. "Equilibre et deséquilibre dans la fonction legislative en droit parlementaire comparé», en Parlament et gouvernement. La partage du pouvoir, Florencia, 1979, pág. 86. También, sobre el mismo tema, V. di Ciolo, Questioni in tema di decreti-legge, Milán, 1970, págs. 237-238.

${ }_{5}^{5}$ Hay ya una advertencia, casi premonitoria, en John Stuart Mill: el Parlamento «sólo debe encargarse directamente de lo que pueda hacer bien. Redúcese su misión en todo lo restante a procurar que sea convenientemente ejecutados; Considerations on Representative Government, 1861 (se cita por la versión española de S. García del Mazo, Madrid, 1878, pág. 128). 
históricamente como insuprimible. El caso norteamericano, así como la aleccionadora experiencia francesa durante la IV República, son los que habría que tener aquí en cuenta sobre todo ${ }^{6}$, y una de las conclusiones a extraer de ello es la de que el problema se traslada al de las fórmulas de control que pueda prever el ordenamiento para encauzar jurídicamente estos fenómenos. Pero, en segundo lugar, no debe perderse de vista que, en un determinado sistema jurídico nacional, los varios medios habilitados para la función normativa del gobierno se encuentran en relación de interdependencia, lo que es especialmente predicable para la incidencia relativa del ejercicio de la potestad reglamentaria y de la utilización de fórmulas delegativas en el ejecutivo. En otras palabras: allá donde la potestad reglamentaria tienda a emanciparse de la necesaria mediación legal en todo caso, los instrumentos de habilitación expresa al ejecutivo pasan a un discreto segundo plano (el caso francés vuelve a ser revelador; desde 1958 hasta 1975 tan sólo han tenido lugar ocho habilitaciones parlamentarias al gobierno en base al art. 38 de la Constitución). Por el contrario, el carácter expansivo de la delegación se advierte en los sistemas en los que - es el caso británico- no existe una potestad general reglamentaria residenciada en el gobierno.

Las consideraciones anteriores creemos que no deben dejar de ser tenidas en cuenta a la hora de iniciar una interpretación de los artículos 82 y siguientes de nuestra Constitución. Con independencia de que la expresión misma «delegación» sea o no un tributo a la tradición del constitucionalismo clásico, es lo cierto que en aquellos preceptos se ha perfilado una regulación de la colaboración Gobierno-Cortes en la función normativa que, con los límites y controles constitucionalmente previstos, puede contribuir eficazmente a equilibrar la «centralidad» parlamentaria en el sistema constitucional y, más concretamente, en el esquema general de fuentes del derecho. Con algunas posibles quiebras importantes (véase, por ejemplo, el art. 96.1 en materia de tratados internacionales), la posición central del Parlamento en nuestro sistema parece debe predicarse tanto en la dimensión del Estado-ordenamiento (débil implantación de los institutos de democracia directa) como en la del Estado-persona, aspecto este último en el que la intensidad con que se afirma el principio de legalidad (arts. 9.3 y 97) y con la que se predica el «sometimiento pleno a la ley y al Derecho» de la Administración (art. 103.1) debe llevar a un muy limitado reconocimiento de la figura del reglamento independiente de ley y a una consiguiente comprensión general de la potestad reglamentaria como ejecutiva de las normas primarias adoptadas por las Cortes ${ }^{7}$. Con independen-

- En cuanto al caso norteamericano, habría que partir de las autorizaciones dadas por el Congreso al presidente Roosevelt para el desarrollo del New Deal (las primeras en base a la Agricultural Adjustment Act y a la National Industrial Recovery Act, ambas de 1933) y anuladas, en un primer momento, por la Corte Suprema. Por lo que se refiere a la IV República francesa, es conocida la expresa prohibición de la delegación legislativa que contenía el artículo 13 de la Constitución de 1947. No obstante, se recurriría a habilitaciones en tal sentido al ejecutivo desde el primer momento. Cuestión diferente es que ello pretendiera ampararse bajo el expediente de la deslegalización y que, para justificar la misma, comenzara a formarse la teoría de las materias «reglamentarias por naturaleza» a partir del fundamental avis del Consejo de Estado de 5-II-1953.

${ }^{7}$ En este sentido, A. Garrorena Morales, El lugar de la ley en la Constitución es- 
cia de la valoración que de lo anterior pueda hacerse $-y$ es evidente que el «temor al ejecutivo» ha estado presente a lo largo del proceso constituyente-, éstos son los rasgos del sistema. Sobre ellos, la delegación legislativa se proyecta como un posible expediente en pro de la coparticipación gubernamental directa en el proceso normativo y en atención a las exigencias propias del Estado contemporáneo.

C) A partir de las consideraciones anteriores, nos proponemos en lás páginas que siguen abordar el problema del control de las normas delegadas sobre la base de la regulación que las mismas han recibido en nuestro texto fundamental, y ello centrando el análisis en uno de los tipos de aquéllas - los textos articulados de leyes de bases-, en atención a su mayor fuerza innovativa en el ordenamiento. Y en este punto hay que señalar que la complejidad del tema obedece a un doble orden de cuestiones. En primer lugar, la ambigua redacción del artículo 82.6 de la Constitución suscita la pregunta en torno a los sujetos mismos del control que pueda ejercerse sobre los decretos legislativos. Es evidente la constitucionalidad de un control parlamentario en este campo - aludido por el mismo artículo 82.6 in fine-, pero las dudas comienzan a la hora de interpretar el sentido de la mención que el mismo precepto hace a «la competencia propia de los Tribunales» y a propósito también de la compatibilización entre este último sistema de control y el que pueda residenciarse ante las Cámaras. ¿Cuál es la «competencia propia» de los Tribunales a que se refiere el artículo 82.6?; más aún, ¿de qué Tribunales se trata? Desde ahora puede decirse que esta remisión constitucional lo es tanto a los Tribunales «ordinarios» - integrados en el poder judicial- como al Tribunal Constitucional. En efecto, si la utilización del plural en el texto de la norma impide considerarla como una alusión exclusiva al órgano de la justicia constitucional en nuestro sistema y, en consecuencia, hay que entender que estamos ante una referencia que incluye también a los órganos de la jurisdicción ordinaria, no es menos evidente que la Constitución ha querido recordar aquí las competencias del Tribunal Constitucional para el enjuiciamiento de normas con fuerza de ley (explícitas en los arts. 161.1.a y 163), puesto que cuando lo que se pretende es una simple referencia a los Tribunales ordinarios la propia Constitución se cuida de significarlo así (véase art. 53.2, en su primer inciso). En una primera aproximación al tema nos encontramos, pues, con la doble intervención, reclamada por el mismo texto constitucional, de la justicia cons-

pañola, Madrid, 1978, pág. 102, y J. L. Carro Fernández Valmayor y R. Gómez-Ferrer Morant, «La potestad reglamentaria del Gobierno y la Constitución», en Documentación Administrativa, núm. 188, págs. 183 y ss. Unas interesantes consideraciones sobre el significado del principio de legalidad en nuestra Constitución y frente al proceso de crisis del Estado de Derecho, en C. de Cabo Martín, «Estado y Estado de Derecho en el capitalismo dominante: aspectos significativos del planteamiento constitucional españols, en Revista de Estudios Políticos, núm. 9, 1979, págs. 113 y ss. Decía Ramón Salas en sus Lecciones de Derecbo público constitucional (vol. I, Madrid, 1821, pág. 150): «Nunca serán de más las precauciones que se tomen contra el poder ejecutivo, que debe mirarse como un enemigo natural de la libertad, siempre en acecho de todas las ocasiones que puedan presentársele para atacarla con ventaja»; la medida en que consideraciones análogas - justificadas, sin duda, ante la experiencia del régimen anterior- puedan haber deparado una relativa inadecuación entre ciertos aspectos de nuestro texto constitucional y determinadas exigencias propias al Estado contemporáneo es algo que deberá ser analizado en otro momento. 
titucional y de la ordinaria, siendo la cuestión a dilucidar la de cuál sea el ámbito respectivo de intervención sobre los decretos legislativos. Y aunque sobre el problema se harán diversas consideraciones más adelante, no sobrará aquí una observación previa que creemos importante: en sí mismo, el artículo 82.6 - por lo que a los Tribunales se refiere - no es norma atributiva de competencias, sino de remisión. Más claramente, se trata de una típica cláusula «sin perjuicio» ${ }^{8}$ mediante la que un subsistema normativo remite a otro y $\sin$ alterar por ello el área ordinaria de competencias atribuidas a los distintos órganos. Esto no significa otra cosa sino que las «competencias propias» a las que dicho precepto se refiere habrán de ser determinadas a la vista del sistema general del ordenamiento, pero no pueden considerarse «creadas» por la sola norma de remisión. Será, por tanto, en las disposiciones constitucionales que delimiten las competencias respectivas de la jurisdicción ordinaria y de la constitucional en donde habremos de buscar los elementos de interpretación necesarios para determinar el alcance del artículo 82.6.

Pero señalábamos antes que la complejidad del precepto que se viene considerando no está sólo en función de su aparente ambigüedad. Existe también toda una línea de interpretación que, formada a partir de una práctica administrativa y judicial previa a la Constitución, tiende a reconocerse en este artículo 82.6 y a interpretarlo, en consecuencia, de acuerdo con construcciones doctrinales que, plenamente operativas durante el régimen anterior, seguramente no lo son tanto a la vista de la nueva estructura constitucional. En este sentido es bien conocida la orientación, bajo el régimen anterior, de una prestigiosa corriente iusadministrativista en pro del control pleno por parte de la jurisdicción ordinaria ( $y$, marcadamente, por parte de los Tribunales contencioso-administrativos) de los decretos legislativos, en base, entre otras razones, a su supuesto carácter de normas sustancialmente reglamentarias ${ }^{9}$. Es indiscutible la oportunidad de tal construcción - sobre la que se volverá en el epígrafe siguiente- teniendo en cuenta las condiciones políticas en que fue concebida, si bien en las actuales circunstancias no puede aceptarse sin importantes matizaciones, no siendo la objeción menor la de que su plena acogida determinaría, según veremos, la configuración como residual del control por parte del Tribunal Constitucional sobre una norma que tiene constitucionalmente atribuido el «rango de ley». Hay que señalar, sin embargo, que es en la dirección que aquí pretende ponderarse hacia donde se ha decantado, con escasas excepciones, la generalidad de la doctrina ${ }^{10}$.

${ }^{8}$ Sobre este tipo de cláusulas, cfr. J. L. Villar Palasí, La interpretación y los apotegmas juridico-lógicos, Madrid, 1975, pág. 173.

9 Cfr., por todos, E. García de Enterría, Legislación delegada, potestad reglamentaria y control judicial, Madrid, 1970, pág. 113, y F. Garrido Falla, «La fiscalización de los decretos legislativos por la jurisdicción contencioso-administrativa», en Revista de Administración Pública, núm. 60,1972, pág. 115. Una postura contraria a estas tesis -aunque matizada, a la vista de las condiciones políticas del régimen anterior- en A. Gil Robles y Gil Delgado, «EI control de legalidad de las normas con fuerza de ley», en Revista Española de Derecbo Administrativo, 1974, págs. 394 y ss.

${ }_{10}$ El mismo planteamiento sigue siendo mantenido actualmente por E. García de Enterría y T. R. Fernández en su Curso de Derecbo administrativo, vol. I, 3. ed., Madrid, 1980 , pág. 235. En parecidos términos, F. Garrido Falla, «Las fuentes del Derecho en la 
II. LOS DECRETOS LEGISLATIVOS COMO FUENTE DEL DERECHO.

SU LOCALIZACION EN EL SISTEMA CONSTITUCIONAL

A) Interpretar el sentido del artículo 82.6 de la Constitución -determinar la competencia del Tribunal Constitucional, así como la que pueda corresponder a la jurisdicción ordinaria- es algo que requiere la previa resolución de dos cuestiones de índole relativamente diferente. Se tratará, en primer lugar, de analizar la categoría «decreto legislativo» como fuente del derecho, lo que supone a su vez tener en cuenta el sistema general de la Constitución - muy particularmente, la forma de gobierno que ésta configuray relacionar con el mismo las diferentes disposiciones aplicables. De otra parte, en un momento posterior, habrá de procurarse una armonización entre los diversos sistemas de control que cabe articular sobre estas disposiciones del Gobierno con fuerza de ley. Sucintamente expuestos, por tanto, los puntos de los que aquí se parte son los siguientes: 1) los decretos legislativos quedan caracterizados, a tenor de lo dispuesto en el artículo 82.1, como normas con rango de ley; en principio, ello conllevaría el control jurisdiccional exclusivo sobre los mismos por parte del Tribunal Constitucional (arts. 161.1.a y 163 de la Constitución y 27.2.b de la Ley Orgánica del Tribunal Constitucional); sin embargo, 2) el propio artículo 82.6 de la Constitución -y, en su desarrollo, el artículo 27.2.b de la LOTC - viene a indicar que la competencia del órgano de la justicia constitucional lo será «sin perjuicio» de la que corresponda, sin mayores precisiones, a los Tribunales integrados en la jurisdicción ordinaria ${ }^{11}$; 3) estamos, por tanto, ante una duplicidad de controles jurisdiccionales que al quedar sólo unilateralmente delimitados por la Constitución —el área de intervención de la jurisdicción ordinaria sigue sin precisarse expresamentese presentan, y así se ha señalado ya ${ }^{12}$, como un foco potencial de inseguridad jurídica; 4) la necesaria delimitación de jurisdicciones en este terreno habrá de determinarse, en fin, tanto mediante la oportuna caracterización como fuente del decreto legislativo (a partir de la que será posible precisar la «competencia propia» sobre los mismos de la jurisdicción ordinaria) como a través de la integración no contradictoria de los dos órdenes de controles aquí considerados.

B) Como hemos intentado apuntar, la cuestión de las eventuales compe-

Constitución española», en La Constitución española y las fuentes del derecho, vol. I, Madrid, 1979, pág. 40. Cfr. también, entre otros, E. Angulo Rodríguez, «Delegaciones legislativas tras la Constitución de 1978», en $\mathrm{La}$ Constitución española y las fuentes del derecbo, ob. cit., págs. 210 y ss. Hasta lo que conozco, la única actitud crítica frente a estas tesis, a partir de la promulgación de la Constitución, ha sido expuesta por A. Serrano en «El principio de legalidad; algunos aspectos problemáticos», en Civitas. Revista Española de Derecho Administrativo, núm. 20, 1979, págs. 93 y 94.

"1 Aunque la fórmula que utiliza el art. 27.2.b de la LOTC es equívoca, entiendo que hay que referirla a «los Tribunales» - distintos del Constitucional- aludidos por el artículo 82.6 de la Constitución.

${ }_{12}$ En este sentido, F. Rubio Llorente y M. Aragón Reyes, «La jurisdicción constitucional», en La Constitución española de 1978 (estudio dirigido por los profesores A. Predieri y E. García de Enterría), Madrid, 1980, pág. 827. 
tencias de los Tribunales integrados en la jurisdicción ordinaria sobre los decretos legislativos suscita no sólo importantes problemas de interpretación, sino también, con mayor alcance, algunas alternativas básicas de política institucional directamente ligadas a la concepción que se mantenga - de acuerdo cori la Constitución- sobre la vinculación del juez a la ley. En nuestro sistema tal vinculación adquiere el carácter de principio general estructurador de la organización del Estado: queda proclamado en el artículo 117.1 (sometimiento «al imperio de la ley» de jueces y magistrados) y corroborado por los ya aludidos artículos 161.1.a y 163, así como por el artículo 106.1, en el que negativamente - siguiendo en esto a la antigua Ley Orgánica del Poder Judicial, en su artículo $7^{13}$ - se excluye del control de los Tribunales las normas con rango superior al reglamentario. Habrá que volver sobre el sentido de algunos de estos preceptos, pero cabe señalar desde ahora que los mismos - definiendo el área constitucional de intervención de la jurisdicción ordinaria- plantean en sus justos términos el problema de la interpretación a dar al artículo 82.6 $\mathrm{y}$ obligan, por tanto, a procturar un ajuste entre disposiciones aparentemente contradictorias.

Claro que el problema apenas existe -0 se disipa inmediatamente- si se parte de la orientación doctrinal a la que ya se ha aludido y que aquí va a intentar ponderarse. En efecto, afirmando que con la técnica de la delegación legislativa estamos ante una asunción anticipada del rango de la norma delegada con carácter condicional -es decir, en tanto en cuanto esta última se mantenga dentro de los límites marcados por la ley delegante-, se ha podido sostener el valor meramente reglamentario de las disposiciones de los decretos legislativos que incurran en ultra vires y, «en consecuencia», reconocer jurisdicción al juez ordinario para determinar tal extralimitación y para adoptar las eventuales medidas - anulación, inaplicación - dispuestas por el ordenamiento frente a los reglamentos ilegales. Es notorio que, si se acoge esta tesis ${ }^{14}$, parecen despejarse todos los problemas que plantea el artículo 82.6 de la Constitución: el decreto legislativo que hubiese incurrido en ultra vires quedaría degradado a norma de rango reglamentario, entrando a conocer del mismo la jurisdicción ordinaria en el ejercicio de su «competencia propia» (y especialmente la jurisdicción contencioso-administrativa, que, de acuerdo con el artículo 1.1 de su Ley reguladora, conoce «de las pretensiones que se deduzcan en relación... con las disposiciones de categoría inferior a la ley»). El juez ordinario lo sería así de la legalidad, «al margen» la competencia del Tribunal Constitucional para el control de la constitucionalidad de la norma delegada. Como veremos en este epígrafe y en el siguiente, ni el desarrollo dogmático que lleva a estas

${ }^{13}$ En desarrollo de la Constitución, esto es también lo que dispone el art. 8 del Proyecto de Ley Orgánica del Poder Judicial (Boletín Oficial de las Cortes Generales de 16-IV-1980, número 129-I): «Los Tribunales controlan el ejercicio de la potestad reglamentaria y la legalidad de la actuación administrativa...»

${ }_{14}$ A reserva de lo que se indica más adelante en el texto, conviene señalar que la tesis de la atribución condicional del rango de ley - cuando así lo indicase 'expresamente la norma delegante- sólo es concebible en las constituciones flexibles y cuando la competencia del gobierno, como legislador delegado, no esté expresamente reconocida. En tales casos -cuando la ley resulta «soberana» sobre la articulación de competencias en el seno del Estado- puede aceptarse que en la delegación se incluya expresamente aquella cláusula. 
conclusiones ni la propuesta en ellas implícita para la delimitación de competencias entre justicia ordinaria y constitucional quedan libres de serias objeciones.

Ya se ha hecho una referencia anteriormente a la plena puntualidad histórica de las tesis aquí comentadas. Su ambiente político-institucional venía definido en el régimen anterior por la absoluta carencia de un control efectivo sobre la legislación delegada adoptada por el Gobierno en base a las habilitaciones de las Cortes. Ni estas últimas - por obvias razones políticas- estaban en condiciones de garantizar, mediante un eventual control a posteriori, el respeto del texto articulado a sus bases legales ni existía una jurisdicción constitucional ante la que poder residenciar la norma presuntamente viciada por ultra vires ${ }^{15}$. Más aún: la propia jurisdicción contencioso-administrativa no sólo consideraba limitada su competencia por el carácter infralegal de las disposiciones impugnadas (art. 1.1 de la LJCA), sino que llegaba en ocasiones -mediante decisiones difícilmente aceptables - a negarse a entrar en la controversia sobre la legalidad de reglamentos cuando éstos traían su fundamento de una expresa remisión legislativa ${ }^{16}$. En este contexto, la tesis de la degradación del rango podía ser el único expediente para propugnar algún tipo de control jurídico sobre el ejercicio gubernamental de la delegación, tal y como, en 1931, había sostenido para el caso italiano Tosato ${ }^{17}$. Por otra parte, parecía poder encontrarse una cierta base argumental a favor de estos planteamientos en determinadas disposiciones singulares que, para subsistemas concretos del ordenamiento, privaban del rango de ley a las normas gubernamentales que se hubiesen dictado en extralimitación de las delegaciones legislativas (aquéllas -dispuso el art. 11.3 de la Ley General Tributaria de 1963- «tendrán la fuerza y eficacia de meras disposiciones administrativas en cuanto excedan de los límites de la autorización o delegación o ésta hubiere caducado por transcurso de plazo o hubiera sido revocada»).

La jurisprudencia, ciertamente, no puede decirse que haya alcanzado una posición unívoca sobre este extremo. Junto a decisiones que se niegan al enjuiciamiento de la adecuación del decreto legislativo a la ley de bases por el carácter de norma con fuerza de ley que aquél ostenta, pueden encontrarse

${ }^{15}$ La alusión a la inexistencia de una jurisdicción constitucional, como dato condicionante de todo este planteamiento, se encuentra en E. García de Enterría, Legislación delegada..., ob. cit., pág. 110 .

${ }_{16}$ Una crítica de esta jurisprudencia puede verse en E. García de Enterría, ibíd., páginas $38 \mathrm{y}$ ss.

${ }_{17} O b$. cit., págs. 187-188. Esta defensa por Tosato de la fiscalización por la jurisdicción ordinaria de la legislación delegada es, sin embargo, plenamente coherente con sus planteamientos. El autor italiano parte de dos premisas fundamentales: 1) el Parlamento no puede delegar su potestad legislativa formal, sobre la que no tiene disiposición, y 2) la "fuerza de ley» está exclusiva e inseparablemente ligada a los actos de las Cámaras (pág. 35: «No es el poder legislativo el que tiene competencia para emanar actos con fuerza de ley, sino que son los actos del poder legislativo los que tienen fuerza de ley»); es notorio que, con estos presupuestos, la norma delegada tiene sólo un carácter legal precario, condicionado, a partir de su naturaleza estrictamente reglamentaria y no siendo concebible otra fuente, distinta de la ley formal, que no sea el reglamento. Lo que no tiene en cuenta Tosato, evidentemente, es el dato - presente en varios ordenamientos contemporáneosde la atomización de la fuerza de ley, tanto en la dimensión del Estadopersona como en la del Estado-ordenamiento. 
otras en las que se da el paso hacia el control del ultra vires —en materia, casi exclusivamente, de textos refundidos- y argumentando para ello la subsistencia del rango de ley sólo dentro de los límites de la delegación ${ }^{18}$. Creemos que, a la vista del nuevo texto constitucional, y ante esta parcial acogida de las tesis de la «degradación del rango» por la jurisprudencia - que no configura, sin embargo, la condición de reiteración en los fallos requerida por el artículo 1.6 del Código Civil-, no pueden dejar de apuntarse algunas consideraciones críticas.

Más adelante se señalarán las dificultades técnicas que provoca - cara a la determinación de la jurisdicción del Tribunal Constitucional- la aceptación del control por parte de la jurisdicción ordinaria de la adecuación de la norma delegada a sus bases legislativas. Por el momento basta con subrayar las objeciones dogmáticas que se suscitan a propósito de la condición misma de aquel control, es decir, acerca de la presunta degradación a rango reglamentario de las disposiciones delegadas en contradicción con su ley de bases.

1. Hay que señalar, en primer lugar, que seguir sosteniendo la pérdida del rango legal de los decretos legislativos y su conversión en reglamentos supone - a la vista de la fuerza normativa inequívocamente atribuida a los mismos por el artículo 82.1 de la Constitución- introducir una peligrosa confusión entre existencia y validez de la norma. La fuerza de ley, como eficacia típica atribuida a un acto por la Constitución, se predica de una disposición a partir de su perfección, con independencia de que la misma pueda resultar inválida. La validez o invalidez de la norma dependerá de la posibilidad de su integración armónica en el ordenamiento (para el caso de los decretos legislativos, básicamente el respeto de la Constitución y de la ley delegante), pero éste será siempre un dato posterior al de su eficacia típica como fuente del derecho, atribuida ex constitutione a partir de su momento perfectivo ${ }^{19}$.

2. Especialmente hay que sostener lo anterior cuando, como en este caso, el texto fundamental no condiciona la fuerza de ley de la disposición a ningún requisito ulterior a su mera perfección. Condición que sí aparece, por ejemplo, a propósito de los decretos-leyes, correctamente caracterizados por el artículo 86.1 como disposiciones - no como normas - «provisionales» ${ }^{20}$. La pro-

${ }_{18}$ Antes de la promulgación de la Constitución, puede citarse la Sentencia del Tribunal Supremo de 20-I-1977, en la que se decide entrar a fiscalizar un texto refundido. Con posterioridad, ya vigente nuestra norma fundamental y también ante un caso de refundición por delegación, el Tribunal Supremo (Sentencia de la Sala Tercera de 27-I-1979) ha venido a considerar constitucionalizadas -en contra de las tesis aquí mantenidas - las orientaciones doctrinales tendentes a la presentación del decreto legislativo como fuente con rango de ley condicionado. Un breve comentario de esta Sentencia puede verse en J. M. Rodríguez Oliver, «La Constitución española en la jurisprudencia del Tribunal Supremo de 1979», en Revista de la Facultad de Derecho (Univ. Complutense), núm. 58, págs. 119-120. Cfr. también la Sentencia de la Sala 2." del Tribunal Supremo de 2 de julio de 1980.

${ }^{19}$ En este sentido - con expresa referencia a las relaciones entre ley delegante y decreto legislativo-- A. Ruggeri, Gerarchia, competenza e qualità nel sistema costituzionale delle fonti normative, Milán, 1977, págs. 178, 186 y 220.

${ }_{20}$ En el decreto-ley, efectivamente, lo provisional, lo contingente, no es la norma (que puede tenet una pretensión de vigencia indefinida), sino la fuente misma. Este es el criterio de diferenciación entre "ordenanza de urgencia» (Notverordnung) y «medida provisional» (Massnabme); en la segunda, como señaló Esposito, «lo provisional, contingente y temporal 
visionalidad del decreto-ley consiste precisamente en que el mismo acto-fuente posee una existencia precaria - limitada en el tiempo- y a la espera de su conversión en ley («convalidación») o eventual derogación. Sin embargo, allá donde el ordenamiento no ha previsto expresamente el sometimiento a condición - del tipo que sea- de la existencia de la fuente no puede el intérprete cuestionar su mismo rango normativo.

3. Conviene observar, también, que las tesis criticadas -en su estuerzo por salvar las dificultades derivadas del artículo 1.1 de la LJCA - no dejan de incurrir en una cierta contradicción lógica al convertir el resultado posible del ejercicio de la jurisdicción en la condición de la misma. Ocurre, en efecto, que el único medio para considerar competente a la jurisdicción contenciosoadministrativa en el control de la adecuación del decreto legislativo a la ley de delegación es el considerar al primero como norma de mero rango reglamentario cuando incurra en ultra vires, extralimitación que, sin embargo, sólo podrá determinarse mediante el ejercicio de la misma jurisdicción.

4. En el fondo - al margen las observaciones anteriores-, lo que subyace en estos planteamientos es la afirmación del carácter sustancialmente reglamentario de las competencias actuadas por el Gobierno en base al artículo 82.1. Se trata de una concepción que ya hace años criticara Esposito ${ }^{21}$ y según la cual la identidad del órgano debería llevar aparejada la identidad del acto en el sistema de fuentes del derecho. Lo contrario, sin embargo, puede ser resueltamente afirmado en nuestro derecho y, en general, respecto de todos aquellos ordenamientos en los que cabe que un mismo órgano adopte actos de diferente eficacia formal. Más concretamente, no hay ninguna razón a favor - y sí algunas en contra- de la afirmación de que las competencias gubernamentales que nacen de la delegación legislativa puedan reconducirse, formal y materialmente, a la genética potestad reglamentaria reconocida en el artículo 97 de la Constitución. Nos encontramos ante una competencia diferente, y ello no sólo porque se actúa mediante actos de distinto rango normativo, sino también porque las disposiciones que en su ejercicio se adopten se encuentran vinculadas a la ley en modo diferente a la sujeción típica que, respecto de aquélla, mantiene el reglamento. Es incuestionable, en este sentido, el mayor margen de autonomía política con que cuenta el legislador delegado para desarrollar los «principios y criterios» (art. 82.4) sentados por la ley de bases. En particular, por lo que a los «criterios» se refiete - y como han señalado Mortati y Cicconetti, entre otros ${ }^{22}-$, debe señalarse su naturaleza de normas orientativas,

es el contenido mismo de la medida»; cfr. La validita delle leggi. Studio sui limiti della potestà legislativa, $i$ vizi degli atti legislativi e il controllo giurisdizionale, Milán, 1964, página $142\left(1 .^{a}\right.$ ed. de 1934).

${ }_{21}$ «(...) la identidad del órgano no conduce a la identidad de valor del acto, y es inexacto todo intento de deducir de la posición del órgano el valor de los actos que por él vienen producidos»; ibíd., pág. 60 .

${ }_{22}$ C. Mortati, Istituzioni di diritto pubblico, vol. II, Padua, 1976, pág. 768 (9. ed.), y S. M. Cicconetti, «I limiti 'ulteriori' della delegazione legislativa», en Rivista Trim. di Diritto Pubblico, núm. 3, 1966, pág. 571. El problema del control de la legalidad, en base a normas finalistas y funcionales, en el Estado de nuestros días ha sido correctamente captado por M. García Pelayo en Las transformaciones del Estado contemporáneo, Madrid, 1977, págs. 66-67. 
preferentemente finalistas, que se adecúan bien a la flexibilidad propia al instituto de la delegación y que, desde luego, no imponen a la norma gubernamental el mismo tipo de sujeción que marca la ley a su reglamento de ejecución. Por lo demás - y aunque se trate de un tema en este momento lateral y sobre el que habrá que volver-, conviene señalar que la identificación entre delegación legislativa y ejercicio de potestad reglamentaria, a fin de fundamentar la competencia de la jurisdicción ordinaria, lleva a consecuencias difícilmente admisibles cuando se pretende proyectar el mismo razonamiento sobre las normas legislativas de las Comunidades Autónomas dictadas al amparo del mecanismo previsto en el artículo 150.1 de la Constitución. Con mayor o menor acierto, es notorio que este precepto (relativo a una cuestión de separación de competencias) se ha querido construir sobre la estructura del artículo 82 (relativo, sin embargo, a la articulación de competencias dentro del Estadopersona) y que no cabe explicarse de otro modo la referencia presente en él a «la competencia de los Tribunales» (que habrá que esforzarse en interpretar de modo que no se contradiga lo dispuesto en el artículo 153, a). Pues bien: si se quiere sostener — como ya se ha apuntado ${ }^{23}$ - que también en el caso de las normas dictadas ex artículo 150.1 sólo se alcanzará el rango legislativo intra vires de la ley marco y que, caso de contradicción entre ambas disposiciones, las primeras tendrán mero valor reglamentario, ¿cómo podrá superarse la objeción de que, en este supuesto, ni siquiera estamos ante un órgano que «ordinariamente» se limite a actuar potestades reglamentarias?; ¿cómo sostener que la Asamblea regional -órgano legiferante, en un sentido formalva a ver degradadas sus disposiciones a rango reglamentario cuando sus competencias propias no se actúan mediante normas secundarias? Como se advierte, la tesis de la degradación en base a la identidad sujeto-acto no puede seguir sosteniéndose.

5. La fuerza de ley, bueno es recordarlo, es una categoría relacional. En este sentido, viene a presentarse como la eficacia formal de determinados actos en base a la que éstos se imponen (aunque de modo distinto) tanto a la Administración como al poder judicial, traduciendo así, en la jerarquía de fuentes del derecho, una decisión política de los constituyentes. En los ordenamientos contemporáneos, el pluricentrismo legislativo ${ }^{24}$ ha deparado que tal fuerza de ley no sea sólo predicable de los actos del Parlamento, sino que se atribuya también a determinadas disposiciones adoptadas por otras instituciones y órganos del Estado, con lo que, sin variarse el sentido político y jurídico de la sumisión del juez y de la Administración a la ley, ya no cabe seguir manteniendo una visión subjetivista de la división de poderes, según la cual el sometimiento a la ley sería sólo el trasunto de la sujeción política al Parlamento. Por el contrario, ante la dislocación del continuo Parlamento-fuerza de ley, la única interpretación posible es la de atender el mandato constitucional en materia de fuentes y no socavarlo, enfrentándole una concepción sobre el Estado que ya

${ }^{23}$ Cfr., por todos, R. Entrena Cuesta, «Comentario al art. 150», en F. Garrido Falla y otros, Comentarios a la Constitución, Madrid, 1980, pág. 1631.

${ }_{24}$ Sobre el tema puede verse A. Predieri, «El sistema de las fuentes del Derechom, en La Constitución española de 1978, ob. cit., págs. 156 y ss. 
no está presente en la norma fundamental. No otra cosa se desprende, por lo demás, del sistema general de nuestra Constitución. El artículo 117.1 sienta el principio del sometimiento del juez a la ley, y en modo alguno cabe entender aquí la expresión «ley» en un sentido restringido (norma primaria de las Cámaras). Dicho sometimiento muestra su alcance constitucional genuino si se coteja el artículo 117.1 con otras dos normas que le enmarcan nítidamente: el artículo 106.1 (que capacita a la jurisdicción ordinaria para enjuiciar la legalidad en el ejercicio de la potestad reglamentaria del Gobierno) y el art. 163 (en donde se impone al juez plantear la cuestión de inconstitucionalidad ante el Tribunal Constitucional cuando considere que una «norma con rango de ley» aplicable al caso pueda contradecir la Constitución).

6. A la vista de lo anterior, ¿qué es lo que se le está pidiendo al juez ordinario cuando se le solicita entrar a conocer de la adecuación de un decreto legislativo a la ley delegante? Este petitum supone, en verdad, un requerimiento para la beterodegradación del rango de la disposición, manipulación sobre el sistema de fuentes que, si se presenta como condición necesaria para afirmar la jurisdicción en base al artículo 1 de la LJCA, carece de todo respaldo constitucional y se encuentra especialmente en contradicción con lo dispuesto en el artículo 1.7 del Código Civil: «Los jueces y tribunales tienen el deber inexcusable de resolver en todo caso los asuntos de que conozcan, ateniéndose al sistema de fuentes establecido.»

C) Si, como hemos intentado subrayar, no cabe fundamentar la «competencia propia» de los Tribunales ordinarios sobre los decretos legislativos en base al presunto carácter reglamentario de los mismos, cuando hubiesen incurrido en ultra vires, ni es tampoco fácil, en consecuencia, reconocer la posibilidad de que aquéllos órganos jurisdiccionales entren a conocer de la adecuación entre norma delegada y delegante, se nos plantea, con todo su alcance, la cuestión de la relación entre una y otra fuente y la de ambas con la Constitución. Sólo a partir de una correcta construcción en este campo será posible destacar el carácter de condición de validez - que no de existencia- que tienen los. límites presentes en la ley delegante sobre el decreto legislativo, así como fundamentar el control prioritario de los mismos a cargo del Tribunal Constitucional.

La confusión sobre el rango formal de los decretos legislativos - fuentes reglamentarias, para unos; «intermedias» entre la ley y el reglamento, según otros; fuentes «atípicas», en fin- no puede fundamentarse en nuestra Constitución (que atribuye indubitadamente rango de ley a estas disposiciones) y sí sólo en un entendimiento que creemos parcial del sistema de fuentes en nuestro derecho. El decreto legislativo no es, desde el punto de vista de la jerarquía, norma infraordenada a la ley formal y tampoco, por tanto, a su propia ley delegante; se encuentra, indudablemente, supeditado a ésta, en el sentido de que habrá de respetar, para ser válido, los distintos límites a que se refiere el artículo 82, pero ello no empaña su rango de ley ni la fuerza típica a éste atribuida. ¿Cómo definir entonces esta relación?; en nuestra opinión, una descripción de la misma se alcanza satisfactoriamente tanto señalando el desajuste parcial, en las normas delegadas, entre eficacia formal y sustancial (Martines) como acudiendo a la distinción entre jerarquía de fuentes y jeraquía de normas 
(Cansacchi y Monaco) ${ }^{25}$. Mediante una u otra formalización, el decreto legislativo aparece materialmente condicionado a la ley delegante sin perder por ello su condición de norma equiparada a la ley formal en la jerarquía de fuentes. $\mathrm{Y}$, correlativamente, la ley de delegación se nos presenta como norma interpuesta ${ }^{26}$, vale decir como norma que media entre la Constitución y el decreto legislativo, precisando, para cada caso concreto, los mandatos de aquélla (artículos 82 y sigs.). No es la ley de delegación el único ejemplo de este tipo de normas interpuestas en nuestra Constitución. Análogo carácter tienen los Reglamentos de las Cámaras (art. 89.1) con arreglo a los que, eventualmente, podrá enjuiciar el Tribunal Constitucional la regularidad formal de las leyes ${ }^{27}$ y una vez ponderada debidamente la clásica tesis contraria al control de los interna corporis; otro tanto cabría decir de la «legislación básica» estatal a la que repetidamente remite el artículo 149.1 de la Constitución, por más que en este caso en modo alguno pueda hablarse de «delegación» (las leyes de delegación son normas habilitantes y limitadoras, en tanto que aquéllas a las que se refiere el artículo 149.1 tienen, respecto de las disposiciones de las Comunidades Autónomas, sólo la segunda condición). Pues bien: en todos estos casos la norma interpuesta se constituye, sí, en condición de validez de las normas derivadas (aunque la «derivación» pueda ser meramente lógica - y no cronológica- como ocurre en los supuestos del artículo 149.1), pero no en su condición de existencia, de modo que la norma que traiga de otra su determinación existirá — si es perfecta - con independencia de que su invalidez pueda ser declarada de acuerdo con el régimen propio de control que le corresponda por su posición en la jerarquía de fuentes (así lo dispone ya el artículo 28.1 de la LOTC -en una norma que habrá que interpretar extensivamente- por lo que se refiere a los actos y disposiciones con fuerza de ley).

En realidad, el fundamento de la relación que media entre ley delegante y delegada no es muy distinto del que puede encontrarse en los demás casos de aplicación del criterio de competencia entre las fuentes. También aquí se trata de equilibrar dos principios que se encuentran en una relativa tensión y que resumen en sí mismos la problemática de la crisis de la fuerza de ley en nuestros días: salvar la preeminencia parlamentaria en el sistema constitucional y reconocer, al tiempo, potestades normativas supraordenadas al reglamento en otros órganos e instituciones del Estado. Así, si el criterio de la competencia tiende en unos casos a garantizar el principio de autonomía en la distribución territorial del poder, en el supuesto de la delegación se trata de subvenir a las peculiares exigencias de la normación en el Estado contemporáneo, escindiendo, como ha señalado Ferri ${ }^{28}$, la unidad de decisión de la ley en las

${ }_{25}$ T. Martines, Diritto costituzionale, Milán, 1978, págs. 69 y ss.; R. Monaco y G. Cansacchi, Lo Stato e il suo ordinamento giuridico, 6. ${ }^{a}$ ed., Turín, 1955, pág. 97.

${ }_{26}$ Acerca del concepto de norma interpuesta -inicialmente expuesto por Lavagna-, cfr. A. Ruggeti, ob. cit., págs. 123 y ss.

${ }^{27}$ F. Rubio Llorente y M. Aragón Reyes, ob. cit., pág. 810.

${ }^{28} \mathrm{G}$. Ferri, «Sulla delegazione legislativa», en Studi di diritto costituzionale in memoria di Luigi Rossi, Milán 1952, pág. 173. Con la evolución del sistema parlamentario y el cese de la oposición orgánica Parlamento-Gobierno, hay que señalar que cambia también la función del instituto de la delegación. La delegación se pone así al servicio del continuo gobierno-mayoría y puede convertirse incluso en un útil expediente de esta última para 
dos fases de determinación de la directiva política y de las normas singulares.

Las consideraciones hechas hasta ahora abundarían en la exclusiva jurisdicción del Tribunal Constitucional por lo que se refiere al control jurídico sobre los decretos legislativos. Este órgano conocería así de una disposición que tiene constitucionalmente atribuido rango de ley (sin que sea posible en nuestro sistema dar trascendencia jurídica a la distinta terminología normativa — «rango» o «fuerza» de ley - toda vez que la expresión utilizada en los artículos 82.1 y 163 es la misma) y apreciaría su adecuación a la Constitución (especialmente a los artículos 82 y sigs.) a través de su relación con la ley delegante. No otra es la doctrina que viene manteniendo la Corte Constitucional italiana -y el italiano es el sistema más próximo al nuestro, por lo que a la delegación se refiere, en el derecho comparado - a partir de sus sentencias iniciales (de 16-I-1957, núm. 3, la primera de ellas). A favor también de la exclusiva jurisdicción del Tribunal Constitucional abogaría la constatación de la insuprimible veta de autonomía política presente en la interpretación gubernamental de las bases legislativas (ejercicio de una potestad, como vimos, distinta a la reglamentaria, sin que se quiera aquí sostener que el desarrollo de una ley por un reglamento supone un mero ejercicio mecánico) y que, tal vez, aconsejaría no reconocer a la jurisdicción ordinaria lo que, parafraseando a Tocqueville ${ }^{29}$, podríamos llamar una «peligrosa eficacia».

Con todo, el artículo 82.6 - con un alcance que no quedó claro a lo largo del proceso constituyente ${ }^{30}$ - así como el artículo $27.2 . b$ de la LOTC, aluden a algún tipo de intervención en este campo de la jurisdicción ordinaria. Los límites jurídicos a esta intervención ya han sido señalados, y en las líneas que siguen se harán algunas consideraciones sobre las posibilidades técnicas de su articulación con el control atribuido al Tribunal Constitucional.

\section{UNA FORMULA DE AJUSTE ENTRE EL CONTROL DE CONSTITUCIONALIDAD Y EL CONTROL DE LEGALIDAD}

A) Si se parte de la base de que, como parece imponer el artículo 82.6 de la Constitución, sobre los decretos legislativos incide un doble tipo de control jurídico a cargo, respectivamente, del Tribunal Constitucional y de los

serlo plenamente, es decir, para superar la tensión en pro de mayorías «más amplias de lo necesario" en que viene a resumirse la tendencia hacia la unanimidad que caracteriza a algunas de las democracias contemporáneas.

${ }^{29}$ De la démocratie en Amérique, 3. ${ }^{\circledR}$ ed., vol. I, París, 1850, pág. 124. La expresión se encuentra en un conocido pasaje en el que Tocqueville observa la imposibilidad del juez norteamericano para proceder a un examen de la constitucionalidad de la ley al margen de un proceso concreto (lo que hoy llamaríamos un control «abstracto»). Para el autor, más que un defecto del sistema, se trata de una de sus mayores virtudes.

${ }^{30} \mathrm{La}$ expresión «sin perjuicio de la competencia propia de los Tribunales» figura ya en el texto del Anteproyecto de Constitución publicado el 5-I-1978 (art. 74.4). Con anterioridad, el borrador publicado en noviembre de 1977 daba un alcance mucho más preciso a esta remisión en su artículo 75.4: «Sin perjuicio de la competencia del Tribunal de Garantías Constitucionales, las Comisiones de las Cortes podrán pedir la suspensión de la legislación delegada en caso de uso incorrecto de la delegación.» 
jueces y Tribunales integrados en la jurisdicción órdinaria, es evidente que el intérprete ha de localizar el criterio -o criterios- que, en la materia, contribuyan a delimitar el área propia de cada uno de estos sistemas de fiscalización. Importa señalar que tales criterios de jurisdicción habrán de serlo plenamente, es decir, deberán proporcionar a los operadores jurídicos y a todos los ciudadanos la certeza básica indispensable al tráfico jurídico, eliminando, en la medida de lo posible, los márgenes de inseguridad que pueden derivarse de la concurrencia de varios medios de control sobre un mismo acto jurídico.

En nuestra opinión, tal criterio de jurisdicción existe, si bien no puede resumirse - con el apresuramiento con que viene haciéndose- en la supuestamente clara distinción entre vicios de ilegalidad y vicios de inconstitucionalidad. Y si no cabe aceptar esta fórmula como solución definitiva, ello se debe a un doble orden de razones: a) En primer lugar, a que, como hemos observado, la misma competencia de la jurisdicción ordinaria para conocer de los posibles vicios invalidantes de una norma con fuerza de ley es, con carácter general, harto discutible $\mathrm{y}$, en todo caso, no puede presentarse como atribución «natural» de tal orden jurisdiccional en lo que se refiere a los decretos legislativos (argumentando, como se viene haciendo, su degradación a norma reglamentaria en el supuesto de ultra vires); $b$ ) Pero es que, como veremos, ni siquiera aceptando hipotéticamente tal criterio las soluciones son satisfactorias: sobre la base de la distinción del tipo de vicio en que haya incurrido el decreto legislativo se puede llegar a una desvirtuación del control de constitucionalidad en nuestro sistema, configurándolo -en abierto contraste con las previsiones constitucionales - como residual y eventual.

No es posible, en primer lugar, ni aun dando por buena la interpretación que quiere ver en el artículo 82.6 una delimitación competencial en base a la distinción entre vicios de ilegalidad y de inconstitucionalidad ${ }^{31}$, suprimir radicalmente la fiscalización del Tribunal Constitucional acerca de la adecuación entre decreto legislativo y ley delegante. Incluso ciñéndonos a los llamados casos de mera ilegalidad de aquél (es decir, contradicción con la ley delegante pero «no con la Constitución») no puede desconocerse que el decreto legislativo incurrirá en inconstitucionalidad por violación de las normas que, en el texto fundamental, regulan el instituto de la delegación y que ante tal contradicción no puede ser indiferente el Tribunal Constitucional ${ }^{32}$. A propósito de esta hipótesis precisa - y al margen de lo que se señalará más adelantedebe destacarse que, en base al artículo 39.2 de la LOTC, «el Tribunal Constitucional podrá fundar la declaración de inconstitucionalidad en la infracción de cualquier precepto constitucional, haya o no sido invocado en el curso del proceso»; pues bien: en aplicación de esta norma, es perfectamente regular y posible que el Tribunal Constitucional, habiendo admitido inicialmente un recurso o una cuestión de inconstitucionalidad por presunta contradicción entre una disposición de un decreto legislativo y alguna norma de la Constitución distinta de las que regulan la delegación legislativa, determine, sin em-

${ }^{31}$ Cfr., por todos, E. Recorder de Casso, «La legislación delegada», en La Constitución española y las fuentes del derecho, ob. cit., vol. III, pág. 1680.

${ }_{32}$ F. Rubio Llorente y M. Aragón Reyes, ob. cit., pág. 827, en el mismo sentido. 
bargo, en su sentencia que la norma impugnada es efectivamente inconstitucional por contraste con alguno de los límites impuestos a las disposiciones delegadas en los artículos 82 a 85 de la Constitución (supuesto de ultra vires). En estos casos - que no son especialmente improbables- el Tribunal Constitucional se limitará a cumplir su función ordinaria, apreciando el ajuste entre la Constitución - toda la Constitución-y las disposiciones y actos con fuerza de ley. Quiere señalarse con lo anterior que los llamados casos de «mera ilegalidad» (ultra vires en sentido estricto) se presentan - cara a la delimitación de los controles invocados por el artículo 82.6- más como una elaboración lógica que como un efectivo criterio, operativo en los casos concretos, para la determinación del ámbito respectivo de intervención de los jueces ordinarios y del Tribunal Constitucional. No hay que olvidar, por lo demás, la imposibilidad de plantear cuestiones de jurisdicción o competencia ante este último órgano, capacitado por su Ley orgánica para determinar autónomamente una y otra (art. $4 .^{\circ}$, núms. 1 y 2 ).

Pero, entrando ya en el núcleo de las tesis que aquí se cuestionan, procede examinar si - con independencia de las objeciones hasta ahora adelantadasla supuestamente clara escisión entre vicios de ilegalidad y de inconstitucionalidad está en condiciones de apuntar criterios útiles y respetuosos con la Constitución para indicar la «competencia propia» de los Tribunales ordinarios en la fiscalización de los decretos legislativos. $Y$ en este punto debe observarse que tal delimitación habría de descansar necesariamente sobre los dos presupuestos siguientes:

a) Eliminación, como parámetro de la constitucionalidad de los decretos legislativos, de los artículos 82 a 85 de la Constitución. En efecto, sólo mediante esta operación es pensable una delimitación conceptual mínimamente clara entre inconstitucionalidad e ilegalidad del decreto legislativo. De otro modo - reconociendo que la norma delegada puede estar «también» en contradicción con las disposiciones constitucionales que regulan, precisamente, la delegación - se llegaría a desdibujar la singularidad misma del vicio de ilegalidad, reconducible siempre, entonces, a una violación de la Constitución.

b) Definición de un criterio «residual» de jurisdicción para los casos, nada improbables, en que se acumulen, sobre una misma disposición, vicios de distinto carácter. Cuando un decreto legislativo incurra en ultra vires y, a su través, en contradicción con alguna norma de la Constitución distinta de las que regulan la delegación legislativa, ca qué órgano corresponderá conocer de la validez o invalidez de dicha disposición? Como se comprende, un criterio de jurisdicción que sea tal —que pretenda establecer delimitaciones ciertas entre las áreas de intervención de varios órganos- habrá de responder claramente a esta pregunta, atribuyendo la competencia, en estos casos de acumulación de vicios, a la jurisdicción ordinaria o al Tribunal Constitucional. Las dos respuestas que ante este problema se han dado - y a las que nos referiremos a continuación - creemos que distan de ser satisfactorias.

En todo caso, tras de estas observaciones previas, conviene analizar más de cerca algunas de las conclusiones a las que se llega mediante la utilización de los mencionados criterios de jurisdicción. Como hemos indicado, tales criterios pretenden ser aplicables en los tres supuestos de invalidez en que podría 
incurrir la norma delegada: 1) mera ilegalidad (ultra vires por violación de la ley de delegación); 2) mera inconstitucionalidad (contradicción con la Constitución, pero respetando los límites impuestos en la delegación), y 3 ) ilegalidad $e$ inconstitucionalidad concurrente (violación de la Constitución a través de la violación de la ley delegante). Según intentaremos evidenciar, en estos tres supuestos - marcadamente en los dos últimos- se advierte la incapacidad del criterio comentado para deslindar las competencias de la jurisdicción ordinaria y de la constitucional con una mínima claridad y dentro del respeto al sistema general de la Constitución.

1. Poco hay que decir, que no se haya indicado ya, acerca de la primera de las situaciones descritas. Sostener que, en los casos de mera ilegalidad, los decretos legislativos podrán ser controlados ( $\mathrm{y}$, eventualmente, anulados o inaplicados) por la jurisdicción ordinaria obliga a la siguiente y difícil argumentación: a) En primer lugar, a determinar que tales casos efectivamente existen, aisladamente de todo problema de constitucionalidad (lo que llevaría no sólo, como vimos, a descartar, en tanto que parámetro de constitucionalidad, los arts. 82 a 85, sino también otros preceptos constitucionales: arts. 9.1, 9.3 y 103.1, entre otros); b) En segundo lugar, a resolver la cuestión de fondo - sobre la que ya se han hecho las suficientes consideracionesplanteada por el enjuiciamiento de una norma con fuerza de ley por el juez ordinario; c) En tercer lugar, a defender que seguirá siendo la jurisdicción ordinaria la llamada a intervenir si un decreto legislativo - presuntamente viciado sólo por ultra vires - afecta al ámbito propio de competencias de una Comunidad Autónoma (lo que supondría no entender aplicable a estos casos lo dispuesto en el art. 32.2 de la LOTC, además de habilitar al juez ordinario para resolver casos de Staatsgerichtsbarkeit); por el contrario, si no se acepta esta solución, habría que concluir que los decretos legislativos son residenciables ante el Tribunal Constitucional cuando se dé el supuesto al que se tefiere el mencionado artículo 32.2, y ello a pesar de que sean «meramente ilegales», lo que llevaría a entender a esta norma como una excepción a la competencia general de la jurisdicción ordinaria y, por tanto, a abocar en la poco razonable conclusión de que el mismo vicio (ultra vires) de una disposición está sometido a un diferente régimen jurídico de control según cuáles sean los sujetos que soliciten su anulación.

2. Por lo que se refiere a los casos de mera inconstitucionalidad, la situación es distinta, pero igualmente rechazable en sus conclusiones. ¿Es pensable un supuesto en que el decreto legislativo, sin violar la ley delegante, incurra en inconstitucionalidad? Sin duda, pero sólo cuando sea inconstitucional la propia ley delegante (la ley de bases, en el caso de los textos articulados). En efecto, estamos ante un caso en que la eventual violación de la Constitución no desborda los límites impuestos en la delegación, lo que sólo puede producirse cuando el vicio de inconstitucionalidad está ya presente en la ley de bases. Desde luego que esta última, como norma independiente que es, puede ser objeto de un recurso de inconstitucionalidad en cualquier momento, pero la situación con la que aquí nos enfrentamos es diferente. Si se adopta como criterio para apreciar la jurisdicción del Tribunal Constitucional el de la mera inconstitucionalidad de las disposiciones impugnadas, es lo cierto que 
el aislamiento de dicho vicio está en función de la previa determinación de la inconstitucionalidad de la ley de bases ( $y$, por tanto, de la adecuación a ésta del decreto legislativo). Ahora bien: tal determinación no deja de ser problemática: a) Cuando la cuestión se suscite ante un órgano judicial, el incidente de inconstitucionalidad que tenga como objeto un decreto legislativo no podría promoverse sin el previo convencimiento judicial de la inconstitucionalidad de la misma ley de bases. Es muy posible que - a la vista de la normal elasticidad de la ley de delegación- el juzgador tienda a «salvar» la constitucionalidad de esta última, atribuyéndose la competencia en lo que ya consideraría caso de simple ultra vires. Ahora bien - al margen de lo que supone este práctico bloqueo del decreto legislativo como objeto de la jurisdicción constitucional-, ¿qué hará el juez o Tribunal si efectivamente detecta sólo un vicio de inconstitucionalidad en la norma delegada? Ciertamente, acudir al Tribunal Constitucional a través de los artículos' 163 de la Constitución y 35 y sigs. de la LOTC; pero ¿qué norma constituye aquí el objeto del incidente y es, en consecuencia, remitida al órgano de la justicia constitucional?, ¿el decreto legislativo?, ¿la ley delegante?, ¿ambas disposiciones? Difícilmente cabe sostener qué objeto de la remisión será la ley de delegación - aisladamente o junto a la disposición delegada - toda vez que la misma no cubre los requisitos a los que se refiere el artículo 163 de la Constitución (la ley de bases no es «aplicable» directamente en el proceso ni la decisión de éste depende de su validez, sino de la del decreto legislativo) y a la vista de que tampoco puede requerirse del Tribunal Constitucional la anulación, a través de un único proceso, de las normas delegante y delegada, ya que este tipo de declaraciones de inconstitucionalidad consecutiva le están vetadas a dicho órgano cuando no se producen en el ámbito de la misma ley (art. 39.1 de la LOTC) ${ }^{33}$. Lo que habría de hacer en estos casos, por tanto, el órgano judicial sería promover el incidente de inconstitucionalidad a propósito sólo del decreto legislativo, argumentando que carece de jurisdicción al no tratarse de un caso de ultra vires... por ser también presuntamente inconstitucional la ley de delegación; b) Como se ve, apenas hay que subrayar las anomalías del procedimiento y el tortuoso sistema que lleva a definir las áreas respectivas de jurisdicción. Pero otro tanto puede decirse en el supuesto de que, efectivamente, la norma delegada se residencie - directamente o mediante la cuestión de inconstitucionalidad- ante el Tribunal Constitucional. En efecto, si se quiere que el criterio delimitador en base a la ilegalidad o a la inconstitucionalidad de la norma impugnada sea plenamente operativo habrá que esperar que sea también tenido en cuenta por el órgano de la justicia constitucional, por más que frente a éste, como vimos, sea impensable suscitar cuestiones de jurisdicción o competencia. ¿Qué significa esto?; obviamente, llevando hasta sus últimas consecuencias las tesis que aquí se discuten, que el Tribunal Constitucional debería negarse a conocer de la validez de la norma delegada cuando dicha validez no se controvierta exclu-

${ }^{33}$ No puede aquí plantearse el problema de las llamadas declaraciones de inconstitucionalidad consecutiva y sí tan sólo hacer referencia a su aparente ámbito restringido de aplicación en nuestro derecho. En el ordenamiento italiano es mayoritaria la tesis de que la invalidez de la ley delegante se propaga al decreto legislativo; cfr. A. Pizzorusso, Fonti del diritto, Bolonia, 1977, pág. 256. 
sivamente en términos de constitucionalidad o inconstitucionalidad. Ahora bien: ¿cómo determinar si estamos ante un tipo u otro de vicio?; nuevamente se plantea aquí la cuestión de la constitucionalidad de la ley de bases como problema previo a la determinación de la jurisdicción competente, y debería ser en este caso el Tribunal Constitucional el que -para confirmar o no su propia jurisdicción - entrase a conocer de la constitucionalidad de la norma delegante. La conclusión es notoriamente absurda, toda vez que no existe cauce, ni constitucional ni legal, para articular esta anómala especie de proceso constitucional previo, que, por lo demás, nadie ha incoado y que, caso de resolverse mediante una declaración de inconstitucionalidad, no tendría efectos inmediatos ni directos sobre la norma efectivamente impugnada (el decreto legislativo) en base a lo dispuesto en el artículo 39.1 de la LOTC.

En realidad, lo absurdo de las conclusiones a las que se llega mediante la aplicación de los criterios de jurisdicción que se han comentado no es sino manifestación de la tesis implícita en los mismos, tesis que sí creemos en contraste tanto con la Constitución como con lo dispuesto en la LOTC. En efecto, tal y como hemos visto, el reconocimiento de jurisdicción en el Tribunal Constitucional sobre los decretos legislativos tan sólo en los casos de mera inconstitucionalidad supone eliminar a la norma delegada como objeto autónomo del proceso constitucional en todos los casos (su legitimidad habría de apreciarse siempre con relación a la propia de la ley delegante) y ello en contra tanto de la inequívoca opción de los constituyentes en el artículo 161.1.a como de lo dispuesto en el artículo 27.2.b de la LOTC. Frente a semejante punto de llegada hay que recordar que la ley de bases y el decreto legislativo son normas con vida propia en el ordenamiento, no siendo aceptable la solución que tiende a plantear los problemas de constitucionalidad de la segunda disposición tan sólo como consecuencia de los vicios en que pueda haber incurrido la primera.

3. ¿Qué ocurre, en fin, en los supuestos en los que se produce concurrencia de vicios de ilegalidad y de inconstitucionalidad en un decreto legislativo? Como venimos señalando, las tesis mayoritarias hasta el momento se pronuncian a favor de la jurisdicción ordinaria en estos casos, por entender que subsiste aquí una cuestión de ilegalidad. Reclamando, de este modo, para sí la jurisdicción ordinaria la resolución de los casos en que la norma delegada viola la Constitución y es, al tiempo, ultra vires, se concluye en la configuración como residual del control por parte de Tribunal Constitucional (que, según hemos visto, sólo conocería del «bloque legal» norma delegante-delegada y no del decreto legislativo como fuente en sí misma).

Frente a esta tesis mayoritaria se apuntó otra en el proceso constituyente de acuerdo con la cual, en los casos de acumulación de vicios de ilegalidad y de inconstitucionalidad, la competencia correspondería al Tribunal Constitucional ${ }^{34}$. Indudablemente, este planteamiento corrige algunas de las insalvables

${ }^{34}$ Esta interpretación fue expuesta por $M$. Fraga Iribarne en la sesión de la Comisión del 2-VI-1978: «La idea de ese número es, como claramente se dice: primero, recordar la competencia de los Tribunales, y no sólo del Constitucional, que sólo intervendría, como es natural, en materia constitucional, sino que normalmente sería en materia de legalidad, es decir, el fenómeno ultra viris, más allá de la autorización. Pero no se excluye 
contradicciones en que el anterior incurre, aunque tampoco queda libre de objeciones. En efecto, si el esquema de delimitación que se acoge es el que reconoce competencia a la jurisdicción ordinaria para conocer en los supuestos de mera ilegalidad y a la constitucional cuando se advierta una presunta violación de la Constitución (acompañada o no de ultra vires), hay que señalar que el fundamento jurídico de uno y otro término de la alternativa es contradictorio. Recordemos que sólo cabría entender competente a la jurisdicción ordinaria para entrar a decidir de la validez de una norma con fuerza de ley cuando se afirme -como se hace a propósito de los decretos legislativos ultra vires y aquí se ha criticado- su degradación a norma de rango reglamentario. $\mathrm{Si}$ se admite hipotéticamente este razonamiento (que sigue estando en la base de la interpretación que ahora comentamos para los casos de mera ilegalidad) no se entiende en base a qué se atribuye al Tribunal Constitucional la competencia en los casos de concurrencia de vicios, toda vez que el ultra vires, inmediatamente, habría determinado la degradación del rango de la disposición, presentándose, entonces, sólo el problema de un reglamento inconstitucional, para conocer del cual sería plenamente competente la jurisdicción ordinaria.

B) Las consideraciones hechas hasta ahora han servido para subrayar las dificultades existentes en nuestro derecho respecto del control, por parte de la jurisdicción ordinaria, de la adecuación entre norma delegada y delegante. Dichas dificultades no hacen sino reconducir el problema de la fiscalización de los decretos legislativos al que, creemos, es su enclave institucional propio, a la vista del sistema general de la Constitución: el control de constitucionalidad de las normas con fuerza de ley por parte del Tribunal Constitucional. Y no se piense que ésta sería una atípica conclusión a la que habría que llegar en nuestro ordenamiento por relación a otros: no conocemos, en nuestra área cultural, ningún sistema en el que el sometimieto del juez a la ley se excepcione frente a las disposiciones delegadas dotadas constitucionalmente de la fuerza de aquélla ${ }^{35}$.

Sin embargo, si la jurisdicción ordinaria no resulta competente para enjuiciar en los casos de ultra vires sí tiene algún tipo de intervención sobre los decretos legislativos. Recordemos, a estos efectos, la cláusula «sin perjuicio»

eventualmente la posibilidad también de la intervención constitucional si se hubiese llegado a tal abuso de la competencia delegada que se hubiese violado la Constitución» (cfr. Diario de Sesiones del Congreso de los Diputados, núm. 80, pág. 2921).

${ }_{35}$ Para el caso francés, y por lo que se refiere a las ordenanzas adoptadas en base al artículo 38, no existe control jurisdiccional a partir del momento en que tales normas han adquirido fuerza de ley, es decir, a partir de la intervención parlamentaria; hasta entonces, las disposiciones del Gobierno tienen mero valor reglamentario (en este sentido, cfr. B. Chantebout, Droit constitutionnel et science politique, París, 1980, pág. 581, y la jurisprudencia allí citada del Consejo Constitucional y del Consejo de Estado). En Gran Bretaña -y al margen el relativo valor, para los sistemas jurídicos continentales, de ciertos aspectos de la práctica jurisdiccional británica- debe señalarse que no en todos los casos la norma delegada gubernamental adquiere fuerza de ley (en este sentido es patente el desuso de la llamada «Cláusula de Enrique VIII», por la que se capacita al Gobierno para modificar leyes del Parlamento). Aunque la cuestión es objeto de debate, existe el criterio de que cuando la norma delegante hace expresa atribución de fuerza de ley a las disposiciones que hayan de dictarse en base a la misma no cabe una fiscalización judicial del ultra vires. Sobre este punto puede verse C. K. Allen, Las fuentes del derecho inglés (trad. de A. Ortiz García), Madrid, 1969, págs. 847 y ss. 
en el artículo 82.6. La misma -como ocurre siempre que se la encuentra en una disposición normativa - tiene dos funciones primordiales. En primer lugar, una función de remisión mediante la que se alude a otro segmento del ordenamiento sin innovar por ello, es decir, sin originar competencias que no existan ya. Función, también, de incomunicación o de no afectación de las competencias meramente aludidas por aquellas que sí son formalizadas en la norma que incluye a la cláusula en cuestión; en el caso que nos ocupa, la incomunicación media entre el control parlamentario y la competencia «propia» de los Tribunales, significándose que por el ejercicio del primero no podrá entenderse descartada la segunda. Ahora bien: si sabemos cual es el ámbito de intervención de la justicia constitucional, no puede decirse lo mismo, por el momento, en lo que se refiere a las «competencias propias» de la jurisdicción ordinaria. Sabemos, eso sí, que las mismas - por la naturaleza de la cláusula de remisión- no podrán exorbitar el marco constitucional dentro del que actúan los jueces y Tribunales ordinarios, y a este respecto cabe recordar el «eje» fundamental constituido por los artículos $117.1,106.1$ y 163 de la Constitución.

¿Cuáles son, en nuestro ordenamiento, las competencias propias a los Tribunales ordinarios que éstos pueden ejercer sobre los decretos legislativos? Desde luego, en primer lugar, las que se ejercen mediante el control de la potestad reglamentaria (arts. 106.1 de la Constitución, 39 de la LJCA y 7.1 de la LOPJ). Y es que, aunque la norma que surge de la delegación no tiene rango reglamentario, sino fuerza de ley, sí pueden adoptarse en base a aquélla disposiciones reglamentarias de desarrollo. En otras palabras: es perfectamente posible que la ley de bases, junto a su función típica de habilitación al Gobierno para adoptar normas con fuerza de ley, prevea la posibilidad de que un reglamento, subsiguiente al decreto legislativo y ejecutivo de éste, venga a completar la regulación de la materia objeto de la delegación. En particular, ello es posible cuando tal materia no esté protegida, en la Constitución, por una reserva absoluta a rango de ley, aunque siempre será necesario que la ley delegante prevea expresamente tal desarrollo reglamentario ulterior (no otro es, en nuestra opinión, el sentido del último inciso del art. 82.3, de desafortunada redacción). Sin embargo, ni se agotan aquí las competencias de la jurisdicción ordinaria ni puede ser éste el único alcance de la remisión del artículo 82.6, toda vez que la fiscalización de los Tribunales sobre los reglamentos está ya expresamente amparada por el citado artículo 106.1 de la Constitución. Compete asimismo a la jurisdicción ordinaria -y éste es el criterio delimitador fundamental respecto de la jurisdicción constitucional- el control sobre los decretos legislativos en cuanto a vicios de procedimiento. Creemos que es ésta la ratio legis que cabe determinar en la remisión del artículo 82.6 a la jurisdicción ordinaria, si se tienen en cuenta todas las observaciones anteriores, así como, en especial, la peculiar fuente del derecho que es el decreto legislativo. Dicho control, exclusivamente sobre vicios formales, tiene la siguiente justificación:

a) En primer lugar, es evidente que, por más que la norma delegada tenga plenamente rango de ley (y que, en tal sentido, huelgue toda distinción entre naturaleza «formalmente» de ley y «materialmente» de reglamento), su elaboración es la propia, con carácter general, de los reglame tos. 
b) En tal sentido, los decretos legislativos están sometidos a todas las : normas que regulan la elaboración de las disposiciones administrativas generales (arts. 129 a 132 de la Ley de Procedimiento Administrativo), así como a las que también sean aplicables para su específico proceso de formación (en concreto, la exigencia de dictamen preceptivo del Consejo de Estado, según el art. 20 de la Ley orgánica 3/1980, de 22 de abril).

c) Estos límites formales tienen, sin embargo, una base exclusivamente legal, por lo que difícilmente podrá ser controlada su observancia por el Tribunal Constitucional. Corresponde, más bien, velar por los mismos a la jurisdicción ordinaria, y especialmente a los Tribunales contencioso-administrativos, con las mismas condiciones y efectos predicables de los recursos (directos. o indirectos) contra reglamentos (en particular, arts. 47.1.c de la LPA y 39 de la LJCA). En base a esta competencia, no puede desconocerse, por tanto, la posibilidad de que un decreto legislativo sea declarado nulo por vicio de procedimiento y sin que ello obste al respeto debido que ha de mantener el juez frente a la fuerza de ley de que está investida la norma. Ocurre aquí, en efecto, que se establece una distinción entre el mandato de la norma y su procedimiento de elaboración. El primero es por completo incontrolable por los Tribunales ordinarios, que no podrán entrar a fiscalizar si el decreto legislativo se adecúa o no a la ley delegante; el segundo, sin embargo, regulado por normas con fuerza de ley y no muy distinto del habitual en la elaboración de disposiciones administrativas generales, sí queda tutelado por la justicia ordinaria. Fuera de estos últimos casos - y a reserva de lo que se indicará a continuación-, el juez o Tribunal que abrigue dudas sobre la validez sustancial de la norma delegada habrá de poner en marcha el dispositivo del artículo 163 de la Constitución (cuestión de inconstitucionalidad).

Subsisten, con todo, algunas dudas respecto del órgano competente para controlar la eventual inobservancia, por parte del Gobierno, de los requisitos de procedimiento adicionales que pueda imponer específicamente la ley de delegación, así como en lo que se refiere al vicio de incompetencia. Hay que decir que la constitucionlidad de aquellas exigencias adicionales no puede cuestionarse, a la vista de lo dispuesto en el artículo 82.6 in fine y de que, como veremos, no hay en principio obstáculo para que el control parlamentario se articule previamente, configurándose, por tanto, como un trámite más en el procedimiento de elaboración del decreto legislativo. En lo que afecta al vicio de incompetencia, el mismo puede producirse tanto porque la norma sea adoptada por autoridad distinta del Gobierno (violación de lo dispuesto en el último inciso del art. 82.3) como ratione temporis, es decir, por el hecho de que el decreto legislativo sea publicado fuera del plazo fijado para el ejercicio de la delegación (véase también lo dispuesto en el art. 82.3). En ambos casos creemos que no puede negarse la jurisdicción del Tribunal Constitucional, si bien sería aconsejable tal vez entender también competentes a los Tribunales ordinarios: en el primer supuesto no dejamos de estar ante un vicio de procedimiento - y un principio de economía procesal abogaría porque fuese determinado con arreglo al sistema general previsto para este tipo de irregularidades- ay en el segundo, la notoriedad propia al vicio de incompeten- 
- cia (en cualquiera de sus dos dimensiones) no plantea especiales dificultades para su control por la jurisdicción ordinaria ${ }^{36}$.

Por último -y aunque esto exorbite un tanto el objeto de este trabajo-, habría que hacer una referencia al sentido de la cláusula «sin perjuicio», también presente en el artículo 150.1 de la Constitución. Ya vimos que, aunque no estemos ante un supuesto de delegación en sentido estricto, los constituyentes han construido en parte este precepto a imagen de la regulación que aquélla recibe en el artículo 82 . No parece posible negar el rango de ley de las disposiciones dictadas por las Comunidades Autónomas ex artículo 150.1 (no una, sino dos veces nos recuerda la Constitución que estamos ante «normas legislativas») $\mathrm{ni}$, en consecuencia, dejar de considerarlas sometidas al control previsto para este tipo de disposiciones en el artículo 153.a. ¿Qué sentido tiene entonces la referencia, de nuevo en plural, a «la competencia de los Tribunales»? Si no queremos concluir en que existe una contradicción insalvable entre los artículos 150.1 y 153.a de la Constitución - y parece que los constituyentes han hecho casi todo lo posible para facilitar esta renuncia del intérprete-, hay que recordar las consideraciones hechas hasta ahora acerca de la imposibilidad de un control sustancial sobre normas con rango de ley por parte de la jurisdicción ordinaria. $Y$, sin embargo, no cabrá aquí, a diferencia de lo que se ha sostenido a propósito de los decretos legislativos, un control formal cuando las normas dictadas en base a la ley marco estatal hayan sido adoptadas por la Asamblea legislativa de la Comunidad Autónoma (imposible control de los interna corporis por otro Tribunal que no sea el constitucional). Ahora bien: ¿es éste el único supuesto?; las normas legislativas a las que se refiere el artículo 150.1 ¿sólo pueden ser adoptadas por la Asamblea comunitaria? Hay que tener en cuenta que nada obsta en la Constitución, cuando existe previsión estatutaria ${ }^{37}$, a que el instituto de la delegación legislativa se ponga en práctica entre la Asamblea y el Consejo de Gobierno. Tampoco el artículo 150.1 se refiere expresamente a la Asamblea comunitaria, sino, genéricamente, a que pueda atribuirse «a las Comunidades Autónomas» la facultad de dictar normas legislativas. Sin duda que, de ordinario, las normas en cuestión serán adoptadas por la Asamblea en tanto que órgano que ostenta la potestad legislativa ordinaria en el ámbito de la Comunidad (art. 152.1), pero no existe obstáculo constitucional a que la propia ley estatal capacite a la Asamblea comunitaria para subdelegar en el Consejo de Gobierno. Con esta expresa habilitación en la ley marco (no prohibida, como en el caso del art. 82.3) decae la eficacia de la regla delegatus delegare non potest y le Consejo de Gobierno será el que articule, en un texto con fuerza de ley, los «principios y bases» fijados en la norma estatal. Es entonces, en estos últimos

${ }^{36}$ Un sector minoritario de la doctrina italiana sostiene la posibilidad de un control por parte de la jurisdicción ordinaria acerca del respeto por el decreto legislativo de los límites y formalidades impuestos por la ley de delegación y que no están basados en el artículo 76 de la Constitución. En todo caso, estos mismos autores -cfr., por ejemplo, Cicconetti, art. cit., pág. 608 - no dudan de la competencia de la Corte Constitucional para conocer en los casos de ultra vires.

${ }^{37}$ Tal previsión se encuentra en el Estatuto de Autonomía de Cataluña (art. 33.1) y en el de Galicia (art. 10.1.a). No existe, sin embargo, una norma semejante en el Estatuto vasco. 
casos, donde puede adquirir un sentido la referencia a los Tribunales en el artículo 150.1: al modo como hemos indicado para el caso de los decretos legislativos, también en estos supuestos podrá la jurisdicción ordinaria entrar a fiscalizar la adecuación formal de la norma comunitaria a las normas legales que regulen su procedimiento de elaboración ${ }^{38}$.

\section{EL CONTROL PARLAMENTARIO}

A) El artículo 82.6 in fine alude a las fórmulas «adicionales» de control que, sobre los decretos legislativos, puedan prever las leyes delegantes en cada caso y «sin perjuicio» de las competencias propias de los Tribunales. Mediante esta norma se cierra el cuadro de controles que vierten sobre la disposición delegada y recuperan las Cámaras - o pueden recuperar- la posibilidad de una decisión final (ya veremos con qué alcance) sobre el ejercicio de la delegación por parte del Gobierno. Tampoco este inciso final del artículo 82.6 quedó a salvo, a lo largo del proceso constituyente, de algunas incoherencias ${ }^{39}$, hoy suprimidas bajo la radical indefinición en que ha quedado la norma. Compete, por tanto, a los Reglamentos de las Cámaras - y en su caso al propio legislador delegante - arbitrar estos sistemas «adicionales» de control y definiri en particular, su momento de intervención y su alcance jurídico. Esta «libertad» en la interpretación de controles no es, sin embargo, absoluta. La lógica de la institución impone unos límites básicos a los que conviene hacer una somera referencia.

$\mathrm{Y}$ antes que nada conviene recordar la vigencia, en el derecho comparado, de determinadas fórmulas de control sobre la legislación delegada. Dejando al margen la ratificación por la Asamblea Nacional francesa de las Ordenanzas gubernamentales (trámite que no es exactamente de control, como veremos, sino de conversión en ley), los dos sistemas que pueden tomarse como referentes son el británico y el italiano. En el primero, el muy frecuente recurso a la delegación en el Gobierno de facultades normativas ha llevado a la articulación de un sofisticado $-\mathrm{y}$, al parecer, no muy eficaz ${ }^{40}$ - sistema de controles

${ }^{38}$ Con lo anterior, por tanto, se quiere subrayar el carácter de normas con fuerza de ley de que estarán dotadas las disposiciones de las Comunidades Autónomas ex artículo 150.1. Si no es aceptable la interpretación que ve en las mismas un mero valor reglamentario, tampoco lo es la afirmación que las configura como normas «intermedias» entre la ley y el teglamento. Acudiendo al expediente de las «fuentes atípicas» ante cada dificultad de interpretación se terminará cayendo en polémicas tan infructuosas - y extenuadas - como las que prosperaron durante la III y la IV República francesa en torno a la naturaleza de los decretos-leyes y como las que sigue manteniendo también un sector de la doctrina italiana.

${ }^{39}$ Así, en tanto que en el texto del borrador y del Ánteproyecto se prevé la posibilidad de que las Comisiones de las Cortes pidan la «suspensión» de la legislación delegada en fase de control parlamentario, el dictamen de la Comisión de Asuntos Constitucionales y libertades públicas transformará dicha intervención parlamentaria en una solicitud de «derogación» en el plazo de seis meses. Hubo que esperar a que en la Comisión de la Cámara Alta el senador Martín Retortillo señalara el absurdo de tal previsión para que la misma desapareciera (cfr. Diario de Sesiones del Senado, núm. 48, sesión de 1-IX-1978, pág. 2205).

* Cfr. Morrison, Government and Parliament. A survey from the inside, 2." edición, Londres, 1966, págs. 162-166 y 303-306; I. Jennings, Parliament, 2." edición, Cambrid- 
parlamentarios, frecuentemente de carácter sucesivo y que en algunos supuestos (a través de la fórmula de la llamada resolución positiva, mediante la que se considera que la norma gubernamental no ha entrado en vigor hasta tanto no haya recaído una votación favorable de la Cámara) tienden a desnaturalizar la idea misma de delegación. Por lo que al caso italiano se refiere, es práctica habitual la de que las leyes de delegación dictadas al amparo del artículo 76 de la Constitución prevean la intervención necesaria de una Comisión interparlamentaria especial y como trámite en el proceso de elaboración de la norma delegada; el parecer de tal Comisión no es, sin embargo, vinculante para el Gobierno y, en todo caso, también aquí la generalidad de la doctrina apunta la relativa ineficacia de este sistema de control ${ }^{41}$.

Entre nosotros es de suponer que el sistema de control parlamentario se inspire en alguna o en varias de estas fórmulas ofrecidas por el derecho comparado. Con todo, creemos que habrán de tenerse en cuenta, para la articulación del control, algunas condiciones o límites derivantes de la naturaleza jurídica misma del instituto de la delegación.

a) En primer lugar, si se articula un sistema de control previo a cargo, por ejemplo, de una Comisión parlamentaria, habrá de cuidarse que la interposición del mismo en el procedimiento de elaboración de la norma delegada no altere el carácter de la misma como disposición gubernamental que es. Esta cautela viene a resumirse en la necesidad de que dicha intervención parlamentaria - pudiendo ser preceptiva para el Gobierno- no debe dar lugar a un dictamen o parecer vinculante. En nuestra opinión, si esto último es lo que se produce estaríamos ya ante un acto complejo -parlamentario y gubernamental- y no ante un acto simple del Gobierno, como creemos que configura al decreto legislativo nuestra Constitución. En todo caso, para lo que sí estaría plenamente capacitada la Comisión consultiva, cuya existencia puede preverse, es para acudir a la posibilidad abierta por el artículo 84 de la Constitución y a la vista del posible uso irregular de la delegación por parte del Gobierno (fundamentar ante la Cámara la conveniencia de adoptar una proposición de ley derogatoria, en todo o en parte, de la norma delegante).

b) Para el caso de que - al margen de que se prevea o no una intervención previa de las Cámaras - se adopte un control a posteriori conviene indicar que el mismo no podrá articularse como trámite de ratificación sin alterar radicalmente las características mismas de la delegación legislativa. No hay que olvidar que el decreto legislativo es norma perfecta desde su promulgación - al margen los vicios de que pueda estar afectada- y que una

ge, 1969, págs. 473 y sigs.; J. Laferrière, «La législation déléguée en Angleterre et le contrôle de son exercice par le Parlement», en L'évolution du droit public. Etudes en l'bonneur d'A. Mestre, París, 1956, págs. 334 y sigs.

${ }^{41}$ A propósito de la relatividad de este control parlamentario, cfr. A. Manzella, «Les fonctions du Parlement en Italie», en L'intégration européenne et l'avenir des parlements en Europe, Luxemburgo, 1975, pág. 111. L. Paladín ha propuesto el que, para determinadas materias de importancia especial, el parecer de las comisiones parlamentarias se configure como vinculante. No creemos - $y$ así se expone en el texto- que tal previsión se concilie con las características de la delegación legislativa (cfr. "Gli atti con forza di legge nelle presenti esperienze costituzionali», en Scritti in onore di C. Mortati, vol. II, Roma, 1977, págs. 470-471). 
de las características de todo sistema de control es, de acuerdo con Galeotti ${ }^{42}$, su accesoriedad respecto del acto principal que es objeto de control, es decir, su carácter, en todo caso, de condición de eficacia, pero no de perfección, del acto de que se trate. Como señalara ya Santi Romano, la ratificación procede «cuando quien puede adoptar un acto jurídico que, sin embargo, ha sido adoptado por quien no tenía tal poder convalida y hace suyo el acto mismo" ${ }^{43}$; en el caso de los decretos legislativos hay una competencia gubernamental, en base a la delegación, que hace inútil hablar de ratificación o convalidación. La consecuencia práctica de ello es que en ningún caso - como se ha hecho y se hace en algunas delegaciones impropias ${ }^{44}$ - puede someterse la entrada en vigor del decreto legislativo a la condición suspensiva de una votación favorable del Parlamento.

B) A propósito del control parlamentario de las disposiciones delegadas pueden volver a suscitarse los tradicionales problemas en torno a la distinción entre control jurídico y de oportunidad, entre jurisdicción y control y acerca también de la eventual mediación en estas cuestiones de la responsabilidad política gubernamental. En cuanto a la oposición entre controles jurídicos y de oportunidad (o políticos), cabe señalar que la misma no es tan nítida como en ocasiones tiende a presentarse ${ }^{45}$. Es notorio que, en tanto que el control jurídico excluye toda apreciación política (o debe excluirla, cuando menos), la inversa puede no darse, es decir, es perfectamente imaginable un trámite de control parlamentario que, definido básicamente como control de oportunidad, incorpore como elementos de juicio estimaciones jurídicas y fundamente en ellas la posible medida en que todo control puede culminar. Con esta matización no hay obstáculo para definir como control político el que pueda producirse en nuestro derecho a raíz de una intervención parlamentaria sobre el decreto legislativo y siempre y cuando se distinga convenientemente entre control y exigencia de responsabilidad política: el primero puede ser sólo ocasión para la segunda, y, en todo caso, una eventual medida desfavorable de control sobre la norma delegada por parte del Parlamento no tiene los efectos, por sí misma, de los mecanismos de responsabilidad institucionalizada del Gobierno.

Ahora bien: ¿en qué consiste jurídicamente el control y cuáles son sus efectos sobre la jurisdicción? En cuanto a la primera pregunta, habría que distinguir los casos de control previo y sucesivo. Si previo, el control se configura como acto integrativo del procedimiento de formación de la norma, y su posible incumplimiento tendrá el mismo alcance jurídıco, como vimos, que el que se reconozca a los demás vicios formales en que pueda incurrir la disposición. En el caso de control a posteriori del decreto legislativo, creemos que aquél y sigs.

42 S. Galeotti, Introduzione alla teoria dei controlli costituzionali, Milán, 1963, págs. 7

${ }_{43}$ Santi Romano, ob. cit., págs. 50-51.

4 "Que el Parlamento - decía G. Ferrari- puede abrogar el decreto legislativo es conforme al ordenamiento, pero debe quedar claro que se trata de abrogación, ya que si, por el contrario, se trata de ratificación o de no ratificación podemos decir que estamos ante la prueba de la inexistencia o invalidez de la delegación»; cfr. Formula e natura dell'attuale decretazione con valore legislativo, Milán, 1948, pág. 136.

${ }^{45}$ Cfr. S. Galeotti, ob. cit., págs. 111 y sigs. 
puede definirse como acto condición —en la terminología de Waline ${ }^{46}$-, es decir, como acto que no perfecciona a una norma ya existente, aunque sí puede condicionar su eficacia. En todo caso, la condición se predica del control mismo y no de la medida eventual a que pueda dar lugar: el requisito de eficacia se cumple, por ejemplo, con el depósito en las Cámaras de la norma delegada - si así se ha exigido-, al margen de que las mismas adopten o no una resolución y del sentido que ésta pueda tener.

Por otra parte $-\mathrm{y}$ respecto del alcance jurídico que pueda reconocerse a este tipo de control sobre los Tribunales-, cabe recordar que el control parlamentario y la jurisdicción son funciones autónomas que no deben interferirse, que pueden actuarse en base a criterios diferentes y tutelar valores también distintos (algo de esto, como vimos, quiere subrayar el art. 82.6 de la Constitución al referirse a que las fórmulas de control parlamentario podrán preverse «sin perjuicio» de la competencia propia de los Tribunales). Más específicamente, debe tenerse en cuenta que el control parlamentario no sana los vicios en que pueda haber incurrido el decreto legislativo. Así, en el caso de que, de modo expreso o tácito, las Cámaras diesen por bueno el uso hecho por el Gobierno de la delegación conferida, tal resolución -o el silencio con eficacia equiparada - no podría obstar, desde luego, al posible control por parte del Tribunal Constitucional de la norma delegada y, en su caso, a la misma declaración de su inconstitucionalidad. Otro tanto cabría decir respecto de los vicios formales del acto, cuyo conocimiento corresponde a la jurisdicción ordinaria: en trámite de control a posteriori las Cámaras no apreciarán el proceso formativo de la disposición delegada, sino, entre otras cosas, su adecuación a la delegación, de tal manera que no existiría obstáculo para un enjuiciamiento posterior de aquélla en el caso de que estuviese presuntamente afectada de vicios invalidantes. En este tema importa no confundir los efectos no sanatorios del control parlamentario con el respeto debido al principio de la división de poderes. En efecto, por más que se reconozca que jurídicamente subsisten los vicios del acto tras de la eventual intervención parlamentaria, es difícil defender una fiscalización a cargo de la jurisdicción ordinaria - no del Tribunal Constitucional- sobre aspectos que ya hayan sido positivamente considerados por parte de las Cámaras ${ }^{47}$. Un ejemplo claro: si se quisiera reconocer -en contra de lo que aquí se ha argumentado- la competencia de los Tribunales ordinarios para enjuiciar los casos de ultra vires en el ejercicio de la delegación, no sería fácil seguir sosteniendo la posibilidad de tal fiscalización una vez que las Cortes se hubiesen pronunciado favorablemente acerca de la adecuación entre norma delegante y delegada ${ }^{48}$.

C) Poco resta por decir a propósito de la articulación concreta del control

46 «Observations sur la gradation des normes juridiques établie par M. Carré de Malberg», en Revue de droit public, 1934, págs. 567 y sigs.

${ }_{47}$ La cuestión ya se planteó bajo el régimen anterior con ocasión de la intervención de la Comisión de Competencia legislativa de las Cortes sobre determinados textos refundidos y por el alcance que a su dictamen dio, en alguna de sus decisiones, el Tribunal Supremo (sentencia de 21-V-1973). Sobre el tema, cfr. Angulo Rodríguez, ob. cit., págs. 208-209.

${ }^{43}$ Independientemente del alcance que tal pronunciamiento pudiera tener -si se hubiesen expresado ambas Cámaras- como una cierta interpretación auténtica de la Ley de delegación. 
parlamentario, cuestión que debe obtener una regulación en los Reglamentos de las Cámaras, a salvo las disposiciones específicas que puedan incorporar las leyes de delegación. Un trámite de control estaba ya previsto en el artículo 61 de la Constitución de 1931 y también aparece en el artículo 134 del vigente Reglamento provisional del Congreso de Diputados. Acerca de esta última disposición -que establece un sistema de comunicación obligada a la Cámara y de «resolución negativa» de ésta sin suspensión de eficacia-, habría que criticar tanto la discutible terminología empleada (en su número $1 .^{\circ}$ se utiliza la expresión «convalidación») como la indefinición en que queda el posible acuerdo del Congreso - -n cuanto a sus efectos jurídicos- en el caso de que se hubiesen formulado «reparos» al uso de la delegación por el Gobierno. Tampoco en el actual Proyecto de Reglamento del Congreso ${ }^{49}$ esta cuestión ha quedado resuelta. En nuestra opinión, los efectos negativos del control sobre el decreto legislativo no pueden consistir -al margen de que se ponga o no en juego la responsabilidad política del Gobierno, que es tema diferente- - sino en su derogación total o parcial por medio de ley y en base al principio del contrarius actus. Como hemos venido indicando, el decreto legislativo es norma perfecta y eficaz desde su adopción por el Gobierno y, naturalmente, con los trámites subsiguientes de promulgación y publicación. Tan sólo en el caso de que así se haya previsto expresamente en los Reglamentos parlamentarios o en las leyes de delegación, el depósito del texto en las Cámaras puede configurarse como acto-condición de eficacia, pero no cabe afirmar los mismos efectos respecto de la medida de control que se pueda adoptar. El decreto legislativo sólo dejará de existir en el ordenamiento mediante su derogación por otra norma del mismo rango ${ }^{50}$.

${ }^{49}$ E1 artículo 152 del Proyecto (Boletín Oficial de las Cortes Generales, núm. 33-I, 11-VI-1980) dispone: «1. Cuando, de conformidad con lo establecido en el artículo $82.6 \mathrm{de}$ la Constitución, las leyes de delegación que establecieren que el control adicional de la legislación delegada se realice por el Congreso de los Diputados, el texto articulado o refundido será publicado en el Boletín Oficial de las Cortes Generales, y si dentro del mes siguiente a su publicación ningún diputado o grupo formulara objeciones, se entenderá que el Gobierno ha hecho uso correcto de la delegación legislativa dentro de los límites fijados por la ley de delegación; 2 . Si dentro del referido plazo se formulara algún reparo a la delegación en escrito dirigido a la Mesa del Congreso, ésta remitirá el escrito a la Comisión correspondiente de la Cámara, que deberá emitir dictamen al respecto en el plazo que al efecto se señale; 3. El dictamen será debatido en el Pleno de la Cámara con arreglo a las normas generales del procedimiento legislativo. A estos efectos, cada observación se considerará como una enmienda; 4 . Los efectos jurídicos del control serán los previstos en la ley de delegación.»

${ }^{50}$ En el supuesto de que los Reglamentos parlamentarios o, en su caso, las leyes de delegación configuren el depósito en las Cámatas del texto gubernamental como condición de control y, al tiempo, de eficacia del acto normativo mismo, lo procedente sería que tal depósito se verificase como acto inmediatamente previo -o simultáneo- a la publicación de la norma en el Boletín Oficial del Estado. De otra forma, si la publicación se ha producido ya, pero no la remisión a las Cámaras, puede abrirse una peligrosa brecha de inseguridad sobre las situaciones jurídicas potencialmente afectadas por la disposición. En general, el tema de las situaciones jurídicas positivas afectadas por el decreto legislativo es el que más problemas puede plantear en fase de control parlamentario. Tal vez por ello sea aconsejable -y no contradictorio con lo que se ha afirmado en el texto acerca de la improcedencia de configurar como condición suspensiva de eficacia a la medida de control- la previsión de un plazo durante el que pudiera solicitarse del Bleno la suspensión cautelar de efectos del decreto legislativo y ante la perspectiva de una eventual medida derogatoria. 